\title{
A review on chemical composition, mechanical properties, and manufacturing work flow of additively manufactured current polymers for interim dental restorations
}

\author{
Revilla-León, Marta ; Meyers, Matthew J ; Zandinejad, Amirali ; Özcan, Mutlu
}

\begin{abstract}
OBJECTIVES Additive manufacturing (AM) technologies can be used to fabricate 3D-printed interim dental restorations. The aim of this review is to report the manufacturing workflow, its chemical composition, and the mechanical properties that may support their clinical application. OVERVIEW These new 3D-printing provisional materials are typically composed of monomers based on acrylic esters or filled hybrid material. The most commonly used AM methods to manufacture dental provisional restorations are stereolithography (SLA) and material jetting (MJ) technologies. To the knowledge of the authors, there is no published article that analyzes the chemical composition of these new 3D-printing materials. Because of protocol disparities, technology selected, and parameters of the printers and material used, it is notably difficult to compare mechanical properties results obtained in different studies. CONCLUSIONS Although there is a growing demand for these high-tech restorations, additional information regarding the chemical composition and mechanical properties of these new provisional printed materials is required. CLINICAL SIGNIFICANCE Additive manufacturing technologies are a current option to fabricate provisional dental restorations; however, there is very limited information regarding its chemical composition and mechanical properties that may support their clinical application.
\end{abstract}

DOI: https://doi.org/10.1111/jerd.12438

Posted at the Zurich Open Repository and Archive, University of Zurich

ZORA URL: https://doi.org/10.5167/uzh-184761

Journal Article

Accepted Version

Originally published at:

Revilla-León, Marta; Meyers, Matthew J; Zandinejad, Amirali; Özcan, Mutlu (2019). A review on chemical composition, mechanical properties, and manufacturing work flow of additively manufactured current polymers for interim dental restorations. Journal of Esthetic and Restorative Dentistry, 31(1):5157.

DOI: https://doi.org/10.1111/jerd.12438 


\section{TITLE}

A review on chemical composition, mechanical properties and manufacturing work flow of additively manufactured current polymers for interim dental restorations. Marta Revilla-León DDS, MSD, a Matthew J. Meyers,b Amirali Zandinejad DDS, MSc,c Mutlu Özcan DDS, DMD, PhDd

aAssistant Faculty and Assistant Program Director AEGD Residency, College of Dentistry, Texas A\&M University, Dallas, TX; Affiliate Faculty Graduate Prosthodontics, School of Dentistry, University of Washington, Seattle, WA: and researcher at Revilla Research Center, Madrid, Spain.

bStudent, College of Dentistry, Texas A\&M University, Dallas, TX

cAssociate Professor and Program Director AEGD Residency, College of Dentistry, Texas A\&M University, Dallas, TX.

dProfessor and Head, Dental Materials Unit, Center for Dental and Oral Medicine, University of Zürich, Switzerland. 


\begin{abstract}
OBJECTIVES: Additive manufacturing (AM) technologies can be used to fabricate 3D printed interim dental restorations. The aim of this review is to report the manufacturing workflow, its chemical composition, and the mechanical properties that may support their clinical application.

OVERVIEW: These new 3D printing provisional materials are typically composed of monomers based on acrylic esters or filled hybrid material. The most commonly used AM methods to manufacture dental provisional restorations are stereolithography (SLA) and material jetting (MJ) technologies. To the knowledge of the authors, there is no published article that analyzes the chemical composition of these new 3D printing materials. Because of protocol disparities, technology selected, and parameters of the printers and material used, it is notably difficult to compare mechanical properties results obtained in different studies.
\end{abstract}

CONCLUSIONS: Although there is a growing demand for these high-tech restorations, additional information regarding the chemical composition and mechanical properties of these new provisional printed materials is required.

Keywords: 3D printing, Additive manufacturing technologies, Interim restorations, Material jetting, Stereolithography. 


\section{INTRODUCTION}

\section{ADDITIVE MANUFACTURING (AM) TECHNOLOGIES}

Additive manufacturing (AM) technologies refer to the fabrication of an object layer-bylayer.1 Advancements in AM technologies have allowed for its integration into the digital workflow of prosthodontic applications. The American Section of the International Association for Testing Materials (ASTM) international standard organization establishes technical standards for a wide range of materials, products, systems, and services. The ASTM committee F42 on AM technologies determined seven AM categories: stereolithography (SLA), material jetting (MJ), material extrusion (ME) or fused deposition modelling (FDM), binder jetting, powder bed fusion (PBF), sheet lamination, and direct energy deposition.1-4 In dentistry, the most commonly used AM methods are SLA and MJ technologies.

For SLA manufacturing, a building platform is immersed in liquid resin which is then polymerized by an ultraviolet laser.5-7 The laser traces a cross-section of each layer. After the layer is polymerized, the building platform descends by a distance equal to the layer thickness, allowing uncured resin to cover the previous layer. This process is repeated several times until the printed object is built.5-8 A scanning mirror directs a precise laser beam at a reservoir of UV sensitive resin to cure the layer (Fig. 1). The depth of cure, which ultimately determines the z-axis resolution, is controlled by the photoinitiator and the irradiant exposure conditions (wavelength, power and exposure time/velocity) as well as any dyes, pigments or other added UV absorbers.9-13

Digital Light Processing (DLP) is considered to be within the same AM category as SLA technology by the ASTM because the technologies share many similarities.1,14 The primary distinction between the SLA and DLP is light source; the cross-sectional image is created by either an arc lamp or semiconductor chip containing a matrix of 
microscopic mirrors, the latter of which is referred to as a Digital Micromirror Device (DMD). Each mirror represents one or more pixels in the projected image. The number of mirrors corresponds to the resolution of the projected image.15 In safelight conditions, light from the DLP projector passes through a UV transparent window and the image is projected onto a vat of liquid photopolymer.15 In this system, the physical object is pulled up from the liquid resin, rather than down and further into the liquid photopolymer. The process is repeated until the $3 \mathrm{D}$ object is built.14,15

Material jetting technology is also referred to as Polyjet Printing (PP), in which a liquid resin is selectively jetted out of hundreds of nozzles and polymerized with ultraviolet light.9 The UV-curable polymers are applied only where desired for the virtual design and, since multiple print nozzles can be used, the supporting material is codeposited. In addition, different variations in color or building material can be designated, including spatially graded structures (Fig. 2).17,18

\section{MANUFACTURING WORKFLOW}

The digital workflow to manufacture a provisional restoration (Fig. 3) with a 3D printer consists of the following sequence: data acquisition, data processing, and manufacturing procedures. 19

- Data acquisition involves digitization procedures normally performed by an extraoral or intraoral scanning (IOS) device (Fig. 3AB), in which the patient's mouth or the working casts are converted into a standard tessellation language (STL) file.

- Data processing involves the virtual design of the provisional restoration using specific CAD software (Fig 3C). Due to the limitations of the AM manufacturing process, specific parameters must be controlled during the digital design. 
Minimum thickness is one such parameter that must be taken into consideration, and this value varies depending on the building material and AM technology used for the fabrication process. CAD software has tools that allow complete control over the thickness of the digital design. It is very important to consider this parameter when processing digital model data for the sake of the printed object's structural integrity (Fig. 5B).

When the design of the object is completed, the STL file is exported to the printer, where build variables and parameters for slicing and adding support structures are specified. This procedure is similar to a $\mathrm{CNC}$ machine that calculates a unique milling protocol for every job it receives. Printer parameters are dependent of the AM technology and the 3D printer.

Other printing parameters that are controlled by the operator include building material, color, and the size of the object. Printing a resilient material may require a different printing angulation, or it may require different ratios and positioning of either supportive material or rigid material. In addition, a risk of overexposure is presented when a clear or transparent object is fabricated, as the light that polymerizes new layers can transfer through newly solidified material to the initial layers of a fabrication. However, this challenge is not present for materials that absorb light more readily. The part's geometry and the chosen print orientation can cause a similar distortion, as light also transfers through the resin tray. Therefore, there should be some strategy when deciding print orientation to minimize potential overexposure when using certain materials and printing certain geometries.

- Manufacturing procedures follows the layer-by-layer buildup of an object using the file on the 3D printer (Fig 6A). In addition to calibrating 3D printers 
periodically, these instruments must be calibrated when room conditions or printer locations change to assure consistency and accuracy. This process of adjustment and fine-tuning compares the readings of an instrument with a standard, thereby check the instrument's accuracy (Fig. 6B).

Post-processing, object cleaning, and post-curing is then performed to complete the polymerization process (Fig 6C-F). Each printer has post-processing recommendations provided by the manufacturer.

\section{RESOLUTION, ACCURACY, PRECISION AND TRUENESS}

Different factors define the capabilities of a 3D printer. These factors summarily reflect the quality of the printed object. Different technologies or printers may vary in suitability, depending on the function of the printed object. For example, a printed provisional restoration requires up to a $125 \mu \mathrm{m}$ marginal and internal fit, which is more specific and restrictive than what is required of a custom tray.20,21

Resolution is the smallest feature that the $3 \mathrm{D}$ printer can reproduce, and it is specific for each technology and printer. The resolution of a 3D printer should be defined on each $\mathrm{x}, \mathrm{y}$, and z-axis in $\mu \mathrm{m}$ or dots per inch (dpi), in which the z-axis normally corresponds to the layer thickness. Precision or repeatability refers to a 3D printer's capacity to manufacture the same object with the same 3D dimensions. Trueness refers to the discrepancy between the printed object and actual dimensions of the desired object.22

Different factors, such as laser speed, intensity, angle and building direction,20-26 number of layers,22,28 software,27 shrinkage between layers,25,28 amount of supportive material,24 and post-processing procedures,28 can affect the accuracy (precision and trueness) of the printed object. Because of protocol disparities, technology selected, and 
parameters of the printers and material used, it is notably difficult to compare results obtained in different studies.

\section{POLYMERS FOR 3D PRINTED INTERIM RESTORATIONS}

\section{Chemical composition}

When performing interim restorations, there are a limited number AM polymers available and approved for intraoral use (Table-1).9 Conventional provisional materials can be divided into two groups according to their chemical composition: those based on monomethacrylates or acrylic resins, and those based on dimethacrylates or bisacryl/composite resins such as bisphenol A-glycidyl dimethacrylate (Bis-GMA) and urethane dimethacrylate (UDMA; these resins are polymerized by light).30-32 AM provisional materials seem to follow the same classification, and some information regarding their chemical composition is listed in table 2 . However, the manufactures did not release all the information that was requested by the authors. It remains unclear if the chemical composition differs from conventional provisional dental materials, as the manufacturing process differs from conventional and $\mathrm{CNC}$ procedures. To the knowledge of the authors, there is no published article that analyzes the chemical composition of these new 3D printing materials.

The food and drug administration (FDA) from the United States Department of Health and Human Services controls and supervises medical devices to determine if they are appropriate for commercial use. Similarly, the European Union (EU) uses CE marking on medical devices that comply with EU regulations, enabling the commercialization of the product in European countries (ISO 13485). 3D printed provisional materials available on the market are CE certified and/or FDA approved. Moreover, a Class IIa CE 
certification generally constitutes low to medium risk, and these devices are certified to be installed within the body between 60 minutes and 30 days.

\section{Mechanical properties}

Understanding the mechanical properties of provisional dental materials is necessary to evaluate newer 3D printing provisional materials, verify the manufacturers' claims, and further compare it with conventional materials to discern an optimal material and a suitable technique for long-term provisional FDPs.20,32,33 Thus, various mechanical properties such as flexural strength, hardness, impact strength, and color stability become critical. Marginal discrepancy, flexural strength and microhardness of provisional materials are important parameters, particularly when the patient must use the provisional restoration for an extended period, when the patient exhibits parafunctional habits or when long-term prostheses are planned.

The mechanical properties of conventional provisional dental materials are better described in the literature.31,34-36 However, authors of the present review attempted to collect a complete description of the mechanical properties of 3D printing provisional materials directly from the manufacturers (table-3 and 4) but not all of the requested information was released.

Digholkar et al37 analyzed and compared the flexural strength and microhardness of printed microfilled hybrid composite (E-Dent 100; Nexdent) (AM group), milled polymethyl methacrylate (PMMA) and conventional PMMA provisional dental materials. There were significant differences in flexural strength values between the AM group (79.54 Mpa), the milled group (104.20 MPa), and the conventional group (95.58 $\mathrm{MPa}$ ). In addition, significant differences were also found between the mean microhardness values (Knoop hardness number) of the AM (32.77), milled (25.33), and 
conventional (27.36) groups. Based on this study, AM provisional material analyzed (Edent 100; Nexdent) presented significantly lower flexural strength but higher microhardness when compared with our current provisional dental materials.

Alharbi et al24 evaluated the effect of printing orientation on the mechanical properties of cylinder-shaped hybrid composite resin printed specimens (Temporis shade A1; DWS). Vertically printed specimens with layers oriented perpendicular to the load direction presented significantly higher compressive strength than horizontally printed specimens with layers parallel to load direction.

Brain at al25 studied the manufacturing tolerance of four polymer AM printers following the manufacturers' parameters. Two geometries were analyzed. The AM material was selected based on the print resolution, specification of the production unit, software, and manufacturing time. Only two of the four printers used the same AM material. Differences in production tolerance were found between the different printers and technologies. The results showed an accuracy from -61 to $92 \mu \mathrm{m}$.

Ide et al26 analyzed the capacity of $3 \mathrm{D}$ printers to reproduce acute angles $\left(60^{\circ}\right.$, $45^{\circ}, 30^{\circ}, 20^{\circ}, 10^{\circ}$, and $5^{\circ}$ ) considering the building printing direction on six triangular prism-shaped specimens using one polyjet and two FDM AM printers. Each printer used a different AM material. They concluded that the dimension production tolerance of the printers of geometry analyzed was less than $1.00 \mathrm{~mm}$ in all the $\mathrm{x}_{-}^{-}, \mathrm{y}_{-}$, and $\mathrm{z}$-axes, but the acute angles could not be reproduced precisely.

Unlike conventional and $\mathrm{CNC}$ manufacturing procedures, $\mathrm{AM}$ technologies enable the production of geometries that are otherwise expensive and time consuming to produce or simply not possible to fabricate. In the case of subtractive technologies, access to small spaces is limited and the bur size impose limitations on the dimensions of a manufactured object.2-4 AM technologies also enable the printing of multiple patterns at 
a time, although the number of patterns will depend on the size of the patterns and the building platform.

Due to the lack of information available, the maximum number of pontics and the minimum size of connectors recommended for $3 \mathrm{D}$ printed provisional restorations remains unclear. It is also uncertain whether these materials can be repaired, or if relining printed objects with conventional materials is a viable option for repair. Furthermore, the behavior of this material over time in a patient's mouth is not well-described.

\section{FUTURE PRESPECTIVES AND CONCLUDING REMARKS}

The rapid development and expansion of applied AM technologies will likely continue as the list of printable dental materials grows. Although there is a growing demand for these high-tech restorations, additional information regarding the chemical composition and mechanical properties of these new materials is required. Understanding how these materials compare with conventional provisional materials will allow for dental professionals to create more robust treatment plans, thereby improving quality of care.

\section{Conflict of Interest}

The authors did not have any commercial interest in any of the materials used in this study. 


\section{TABLES}

Table 1. Summary of some additively manufactured polymers, approved for interim dental applications, provided by the manufacturers.

\begin{tabular}{|c|c|c|c|}
\hline BRAND & NAME & $\begin{array}{l}\text { DEFINITION } \\
\text { CERTIFICATION PROVIDED }\end{array}$ & $\begin{array}{c}\text { WAVELENGTH } \\
(\mathrm{nm})\end{array}$ \\
\hline Detax & FreePrint Temp & $\begin{array}{l}\text { Monomer based on acrylic esters } \\
\text { for manufacturing of 3D-printed } \\
\text { crowns and bridges } \\
\text { based on acrylic esters. } \\
\text { Class IIa CE Certified } \\
\text { Not FDA-approved }\end{array}$ & $\begin{array}{l}\text { LED UV } 405 \\
\text { or } \\
378-388\end{array}$ \\
\hline DWS & Temporis & $\begin{array}{l}\text { Light curable nanocomposite } \\
\text { Class IIa CE Certified } \\
\text { Not FDA-Approved }\end{array}$ & $405 \mathrm{~nm}$ \\
\hline \multirow{2}{*}{ Envisiontec } & E-Dent 100 & $\begin{array}{l}\text { Micro filled hybrid material } \\
\text { Class IIa CE Certified }\end{array}$ & \multirow{2}{*}{$365-405$} \\
\hline & E-Dent 400 & $\begin{array}{l}\text { Class IIa CE Certified } \\
\text { FDA-approved }\end{array}$ & \\
\hline \multirow{2}{*}{$\begin{array}{l}\text { Nextdent } \\
\text { (Vertex } \\
\text { dental) }\end{array}$} & $C \& B$ & $\begin{array}{l}\text { Micro filled aterial } \\
\text { Class IIa CE Certified. } \\
\text { FDA-approved }\end{array}$ & \multirow{2}{*}{$\begin{array}{c}\text { Blue UV-A } \\
(315-400) \\
+ \\
\text { UV-Blue } \\
(400-550)\end{array}$} \\
\hline & C\&B MFH & $\begin{array}{l}\text { Micro filled hybrid material } \\
\text { Class IIa CE Certified } \\
\text { FDA-approved }\end{array}$ & \\
\hline Stratasys & VeroGlaze - MED620 & $\begin{array}{l}\text { Not Class IIa CE Certified } \\
\text { Not FDA-approved }\end{array}$ & $200-400$ \\
\hline
\end{tabular}


Table 2: Summary of chemical composition of the additively manufactured polymers, approved for interim dental applications, provided by the manufacturers.

\begin{tabular}{|c|c|c|c|}
\hline BRAND & NAME & CHEMICAL COMPOSITION & $\begin{array}{l}\text { INORGANIC } \\
\text { FILLER (weight\%) }\end{array}$ \\
\hline Detax & $\begin{array}{l}\text { Freeprint } \\
\text { Temp }\end{array}$ & $\mathrm{NP}^{*}$ & NP* \\
\hline DWS & Temporis & $\begin{array}{c}\text { Mixture of multi-functional acrylic monomers, } \\
\text { Esters of acrylic acid }\end{array}$ & NP* \\
\hline \multirow[t]{2}{*}{ Envisiontec } & E-Dent 100 & $\begin{array}{l}\text { Tetrahydrofurfuryl methacrylate, urethane } \\
\text { dimethacrilate, phosphinoxide and } \\
\text { multifunctional acrylic resins }\end{array}$ & $\begin{array}{c}49,8 \\
(0.04-0.7 \text { micron } \\
\text { particle size of } \\
\text { inorganic fillers) }\end{array}$ \\
\hline & E-Dent 400 & Monomer based on acrylic esters & NP* \\
\hline \multirow{2}{*}{ Nextdent } & $\mathrm{C} \& \mathrm{~B}$ & NP* & NP* \\
\hline & C\&B MFH & NP* & $\mathrm{NP}^{*}$ \\
\hline Stratasys & $\begin{array}{l}\text { VeroGlaze } \\
\text { MED620 }\end{array}$ & $\begin{array}{l}\text { 2-Hydroxy-3-phenoxypropyl acrylate } \\
\text { 4-(1-oxo-2propenyl) morpholine } \\
\text { Exo-1, } 7 \\
\text { 7-trimethylbicyclo[2.2.1]hept-2-yl acrylate } \\
\text { Tricyclodecane Dimethanol Diacrylate } \\
\text { Bisphenol-A epoxy acrylate oligomer, } 2,4,6 \\
\text { Trimethylbenzoyldiphenylphosphine oxide }\end{array}$ & $\mathrm{NP}^{*}$ \\
\hline
\end{tabular}

*NP: Not provided 
Table 3. Summary of the mechanical properties of AM polymers available on the market for interim dental applications, provided by the manufacturers.

\begin{tabular}{|c|c|c|c|c|c|c|c|}
\hline $\begin{array}{l}\text { MECHANICAL } \\
\text { PROPERTY }\end{array}$ & $\begin{array}{l}\text { Freeprint Temp } \\
\text { DETAX }\end{array}$ & $\begin{array}{l}\text { Temporis } \\
\text { DWS }\end{array}$ & $\begin{array}{c}\text { E-Dent } 100 \\
\text { ENVISIONTEC }\end{array}$ & $\begin{array}{c}\text { E-Dent } 400 \\
\text { ENVISIONTEC }\end{array}$ & $\begin{array}{c}\text { C\&B } \\
\text { NEXTDENT }\end{array}$ & $\begin{array}{c}\text { C\&B MFH } \\
\text { NEXTDENT }\end{array}$ & $\begin{array}{c}\text { VeroGlaze } \\
\text { MED620 } \\
\text { STRATASYS } \\
\end{array}$ \\
\hline Colors & $\mathrm{A} 1, \mathrm{~A} 2, \mathrm{~A} 3$ & $\begin{array}{l}\mathrm{N}, \mathrm{A} 1, \mathrm{~A} 2, \mathrm{~A} 3, \\
\mathrm{~A} 3.5, \mathrm{~B} 1 \\
\end{array}$ & $\mathrm{~A} 1, \mathrm{~A} 2, \mathrm{~A} 3$ & A 3.5 & $\mathrm{~A} 2, \mathrm{~A} 3.5$ & $\mathrm{~A} 2, \mathrm{~A} 3.5$ & $\mathrm{~A} 2$ \\
\hline Tensile strength (MPa) & NP* & $35-50$ & $30 \mathrm{~N} / \mathrm{mm} 2$ & $\mathrm{NP}^{*}$ & $\mathrm{NP}^{*}$ & $\mathrm{NP}^{*}$ & $54-65$ \\
\hline Elongation at break (\%) & NP* & $2-3$ & NP* & $\mathrm{NP}^{*}$ & $\mathrm{NP}^{*}$ & NP* & $15-25$ \\
\hline Flexural strength $(\mathrm{MPa})$ & NP* & $85-135$ & $>100$ & 85 & $85-100$ & $100-130$ & $80-110$ \\
\hline Modulus of elasticity (MPa) & NP* & $2900-4200$ & $>4500$ & 2100 & $2300-2500$ & $2400-2600$ & $2200-3200$ \\
\hline Water sorption & NP* & $<40\left(\mathrm{mg} / \mu \mathrm{m}_{3}\right)$ & $18.1\left(\mu \mathrm{g} / \mathrm{mm}_{3}\right)$ & $30\left(\mu \mathrm{g} / \mathrm{mm}_{3}\right)$ & $<30$ & $<30$ & $1.2-1.5$ \\
\hline Water solubility & NP* & $<1.4\left(\mathrm{mg} / \mu \mathrm{m}_{3}\right)$ & $5\left(\mu \mathrm{g} / \mathrm{mm}_{3}\right)$ & $5\left(\mu \mathrm{g} / \mathrm{mm}_{3}\right)$ & $<5$ & $<5$ & NP* \\
\hline Hardness Shore D & NP* & $91-93$ & NP* & $89-90$ & $80-90$ & $\mathrm{NP}^{*}$ & $83-86$ \\
\hline Vickers hardness (HV) & NP* & NP* & 25 & NP* & NP* & $\mathrm{NP}^{*}$ & $\mathrm{NP}^{*}$ \\
\hline $\begin{array}{l}\text { Maximum recommended } \\
\text { time in the intraoral } \\
\text { environment }\end{array}$ & NP* & 6 months & 1 Year & 1 Year & $\mathrm{NP} *$ & $\mathrm{NP}^{*}$ & Up to $24 h$ \\
\hline $\begin{array}{l}\text { Minimum area } \\
\text { recommended for connector } \\
\text { Anterior bridges }(\mathrm{mm} 2)\end{array}$ & $\mathrm{NP} *$ & $\mathrm{NP}^{*}$ & 12 & 12 & $\mathrm{NP} *$ & $\mathrm{NP}^{*}$ & NP* \\
\hline $\begin{array}{l}\text { Minimum area } \\
\text { recommended for connector } \\
\text { Posterior bridges }(\mathrm{mm} 2)\end{array}$ & $\mathrm{NP}^{*}$ & $\mathrm{NP}^{*}$ & 14 & 14 & NP* & $\mathrm{NP}^{*}$ & NP* \\
\hline $\begin{array}{l}\text { Minimum wall thickness } \\
\text { Occlusal }(\mathrm{mm})\end{array}$ & NP* & $\mathrm{NP} *$ & 2 & 2 & $\mathrm{NP} *$ & $\mathrm{NP}^{*}$ & NP* \\
\hline $\begin{array}{l}\text { Minimum wall thickness } \\
\text { Circumferential (mm) }\end{array}$ & $\mathrm{NP} *$ & $\mathrm{NP}^{*}$ & 1.5 & 1.5 & $\mathrm{NP}^{*}$ & $\mathrm{NP}^{*}$ & NP* \\
\hline
\end{tabular}

\section{*NP: Not provided}


Table 4. Summary of the hazards identification of the AM polymers available on the market for interim dental applications.

\begin{tabular}{|c|c|c|c|c|c|c|c|}
\hline $\begin{array}{l}\text { HAZARD } \\
\text { IDENTIFICATION }\end{array}$ & $\begin{array}{l}\text { Freeprint Temp } \\
\text { DETAX }\end{array}$ & $\begin{array}{l}\text { Temporaris } \\
\text { DWS }\end{array}$ & $\begin{array}{l}\text { E-Dent } 100 \\
\text { ENVISIONTEC }\end{array}$ & $\begin{array}{l}\text { E-Dent } 400 \\
\text { ENVISIONTEC }\end{array}$ & $\begin{array}{l}\text { C\&B } \\
\text { NEXTDENT }\end{array}$ & $\begin{array}{l}\text { C\&B MFH } \\
\text { NEXTDENT }\end{array}$ & $\begin{array}{l}\text { VeroGlaze } \\
\text { MED620 } \\
\text { STRATASYS }\end{array}$ \\
\hline Acute toxicity & NP* & $\mathrm{NP}^{*}$ & $\mathrm{NP}^{*}$ & $\mathrm{NP}^{*}$ & $\mathrm{NP}^{*}$ & $\mathrm{NP}^{*}$ & Category 4 \\
\hline Skin corrosion/irritation & $\mathrm{NP}^{*}$ & Category 2 & $\mathrm{NP}^{*}$ & $\mathrm{NP}^{*}$ & $\mathrm{NP}^{*}$ & $\mathrm{NP}^{*}$ & Category 2 \\
\hline Serious eyes damage/irritation & $\mathrm{NP} *$ & Category 2 & $\mathrm{NP}^{*}$ & $\mathrm{NP}^{*}$ & $\mathrm{NP}^{*}$ & $\mathrm{NP}^{*}$ & Category 1 \\
\hline Skin sensitization & NP* & Category 1 & $\mathrm{NP}^{*}$ & Category 1 & $\mathrm{NP}^{*}$ & $\mathrm{NP}^{*}$ & Category 1B \\
\hline $\begin{array}{l}\text { Specific target organ toxicity } \\
\text { (single exposure) }\end{array}$ & $\mathrm{NP}^{*}$ & $\mathrm{NP}^{*}$ & NP* & $\mathrm{NP}^{*}$ & $\mathrm{NP}^{*}$ & $\mathrm{NP}^{*}$ & Category 3 \\
\hline $\begin{array}{l}\text { Specific target organ toxicity } \\
\text { (repeated exposure) }\end{array}$ & $\mathrm{NP}^{*}$ & $\mathrm{NP}^{*}$ & $\mathrm{NP}^{*}$ & $\mathrm{NP}^{*}$ & $\mathrm{NP}^{*}$ & $\mathrm{NP}^{*}$ & Category 2 \\
\hline Acute aquatic toxicity & $\mathrm{NP}^{*}$ & $\mathrm{NP}^{*}$ & NP* & NP* & $\mathrm{NP}^{*}$ & $\mathrm{NP}^{*}$ & Category 1 \\
\hline Chronic aquatic toxicity & NP* & NP* & NP* & Category 4 & $\mathrm{NP}^{*}$ & $\mathrm{NP}^{*}$ & Category 1 \\
\hline
\end{tabular}




\section{REFERENCES}

1. ASTM, Committee F42 on Additive Manufacturing Technologies, West Conshohocken, Pa. 2009 Standard terminology for additive manufacturing - general principles and terminology. ISO/ASTM52900-15.

2. Azari A, Nikzad S. The evolution of rapid prototyping in dentistry: a review. Rapid Prototyping J., 2009;15:216-25.

3. Horn TJ, Harrysson OL. Overview of current additive manufacturing technologies and selected applications. Sci Prog., 2012;95:255-82.

4. Revilla-León M, Özcan M. Additive Manufacturing Technologies Used for Processing Polymers: Current Status and Potential Application in Prosthetic Dentistry. J Prosthodont., 2018 [Epub ahead of print].

5. Hull CW. Apparatus for production of three-dimensional objects by stereolithography, US Patent 4575330, 1986.

6. Hull CW, Spence ST, Albert DJ, et al. Method and apparatus for production of threedimensional objects by stereolithography, US Patent 5059359, 1991.

7. André JC, Cabrera M, Jezequel JY, et al. Process for producing a model of an industrial component and device for implementing this process. French Patent 2583333, 1985.

8. André JC, Méhauté A, Witthe O. Dispositif pour realiser un module de piece industrielle, French Patent 8411241, 1984.

9. Stansbury JW, Idacavage MJ. 3D printing with polymers: Challenges among expanding options and opportunities. Dent Mater., 2016;32:54-64.

10. Liska R, Schuster M, Infuhr R, et al. Photopolymers for rapid prototyping. J Coatings Technol Res., 2007;4:505-10. 
11. Infuehr R, Pucher N, Heller C. Functional polymers by two-photon 3D lithography. Appl Surface Sci., 2007;254:836-40.

12. Reeves P. Additive Manufacturing - A supply chain wide response to economic uncertainty and environmental sustainability. 2009. Econolyst Limited, The Silversmiths, Derbyshire, UK.

13. Petrovic V, Gonzalez JVH, Ferrando OJ, et al. Additive layered manufacturing: sectors of industrial application shown through case studies. Int J Prod Res., 2011;49:1061-79.

14. Hornbeck L. Digital Micromirror Device. US Patent No. 5.061.049. 2009.

15. Groth C, Kravitz ND, Jones PE, et al. Three-dimensional printing technology. J Clin Orthod., 2014;48:475-85.

16. Bartolo PJ. Stereolithography: Materials, Processes and Applications. Ed. Springer, 2011, pp. 81-111.

17. Singh V. Rapid Prototyping, Materials for RP and Applications of RP. Int J Eng Res., Sci 2013;4:473-80.

18. Fahad M, Dickens P, Gilbert M. Novel polymeric support materials for jetting based additive manufacturing processes. Rapid Prototyp J., 2013;19:230-39.

19. Fahad M, Dickens P, Gilbert M. Novel polymeric support materials for jetting based additive manufacturing processes. Rapid Prototyp J., 2013;19:230-39.

20. Christensen GJ. Marginal fit of gold inlay castings. J Prosthet Dent., 1966;16:297305 .

21. McLean JW, Von Fraunhofer JA. The estimation of cement film thickness by an in vivo technique. Br Dent J., 1971;131:107-11. 
22. Puebla K, Arcaute K, Quintana R, et al. Effects of environmental conditions, aging, and build orientations on the mechanical properties of ASTM type I specimens manufactured via stereolithography. Rapid Prototyp J., 2012;18:374-88.

23. llen S, Dutta D. On the computation of part orientation using support structures in layered manufacturing. Austin, TX, Proceedings of the Solid Freeform Fabrication Symposium, 1994, pp. 259-69.

24. Alharbi N, Osman R, Wismeijer D. Effect of build direction on the mechanical properties of 3D printed complete coverage interim dental restorations. J Prosthet Dent., 2016;155:760-67.

25. Brain M, Jimbo R, Wennenberg A. Production tolerance of additive manufactured polymeric objects for clinical applications. Dent Mater., 2016;32:853-61.

26. Ide $\mathrm{Y}$, Nayar S, Logan $\mathrm{H}$, et al. The effect of the angle of acuteness of additive manufactured models and the direction of printing on the dimensional fidelity: clinical implications. Odontology., 2017;105:108-15.

27. Plooji JM, Maal TJ, Haers P, et al. Digital three-dimensional image fusion processes for planning and evaluating orthodontics and orthognathic surgery. A systematic review. Int J Maxillofac Surg., 2011;40:341-52.

28. Tahayeri A, Morgan M, Fugolin AP, et al. 3D printed versus conventionally cured provisional crown and bridge dental materials. Dent Mater., 2018;34:192-200.

29. Vahidi F. The provisional restoration. Dent Clin N Am., 1987;31:363-81.

30. Anusavice KJ. Dental Polymers. Philips' Science of Dental Materials 10th ed. Elsevier Science, 1996. pp.143-70.

31. Astudillo-Rubio D, Delgado-Gaete A, Bellot-Arcís C,et al. Mechanical properties of provisional dental materials: A systematic review and meta-analysis. PLos One., 2018;13: e0193162. 
32. Gegauff AG, Holloway JA. Provisional Restorations. In: Rosenstiel SF, Land MF, Fujimoto J, editors. Contemporary Fixed Prosthodontics. St. Louis: Mosby; 2001. pp. 380- 416 .

33. Gratton DG, Aquilino SA. Interim restorations. Dent Clin N Am., 2004;48:487-97.

34. Burns DR, Beck DA, Nelson SK. A review of selected dental literature on contemporary provisional fixed prosthodontic treatment: Report of the committee on research in fixed prosthodontics of the Academy of Fixed Prosthodontics. J Prosthet Dent., 2003;90:474-97.

35. Balkenhol M, Ferger P, Mautner MC, et al. Provisional crown and fixed partial denture materials: mechanical properties and degree of conversion. Dent Mater., 2007;23:1574-83.

36. Balkenhol M, Mautner MC, Ferger P, et al. Mechanical properties of provisional crown and bridge materials: chemical-curing versus dual-curing systems. J Dent., 2008;36:15-20.

37. Digholkar S, Madhav VN, Palaskar J. Evaluation of the flexural strength and microhardness of provisional crown and bridge materials fabricated by different methods. J Indian Prosthodont Soc., 2016;16:328-34.

38. Monaco C, Scheda L, Ciocca L, et al. The prototype concept in a full digital implant workflow. J Am Dent Assoc., 2018 [Epub ahead of print]. 


\section{FIGURES}

Figure 1. Stereolithography AM technology scheme. Illustration courtesy of Additively.com.

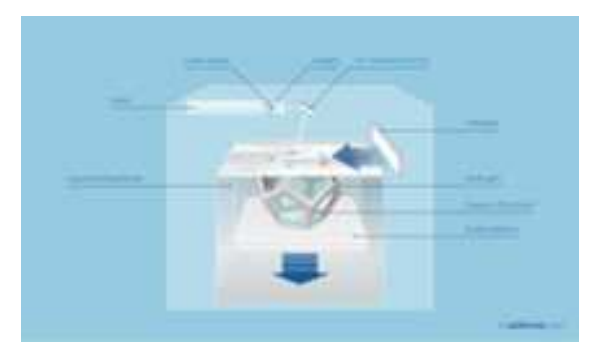

Figure 2. Material jetting 3D printing technology scheme. Illustration courtesy of Additively.com.

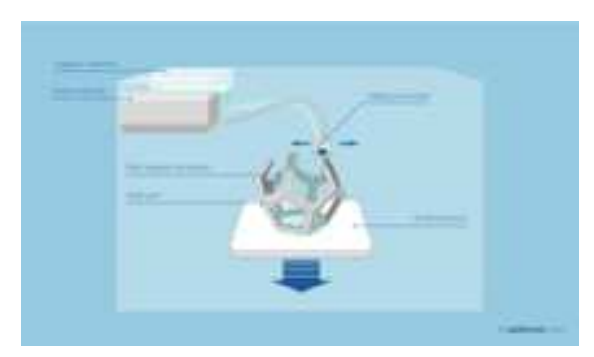

Figure 3. Additively manufactured interim dental restoration before the removal of the supportive structures.

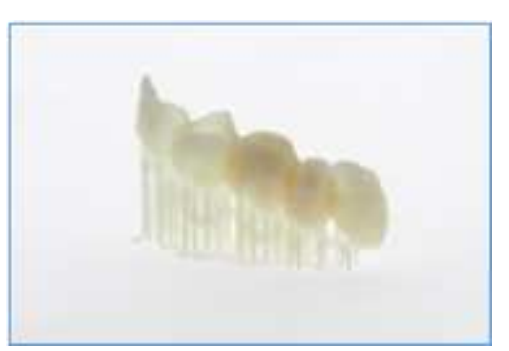

